\title{
COMPARISON OF THE RADIATIVE TWO-FLUX AND DIFFUSION APPROXIMATIONS
}

Charles M. Spuckler

NASA Glenn Research Center

21000 Brookpark Rd.

Cleveland Ohio 44135

\begin{abstract}
Approximate solutions are sometimes used to determine the heat transfer and temperatures in a semitransparent material in which conduction and thermal radiation are acting. A comparison of the Milne-Eddington two-flux approximation and the diffusion approximation for combined conduction and radiation heat transfer in a ceramic material was preformed to determine the accuracy of the diffusion solution. A plane gray semitransparent layer without a substrate and a non-gray semitransparent plane layer on an opaque substrate were considered. For the plane gray layer the material is semitransparent for all wavelengths and the scattering and absorption coefficients do not vary with wavelength. For the non-gray plane layer the material is semitransparent with constant absorption and scattering coefficients up to a specified wavelength. At higher wavelengths the non-gray plane layer is assumed to be opaque. The layers are heated on one side and cooled on the other by diffuse radiation and convection. The scattering and absorption coefficients were varied. The error in the diffusion approximation compared to the Milne-Eddington two flux approximation was obtained as a function of scattering coefficient and absorption coefficient. The percent difference in interface temperatures and heat flux through the layer obtained using the Milne-Eddington two-flux and diffusion approximations are presented as a function of scattering coefficient and absorption coefficient. The largest errors occur for high scattering and low absorption except for the back surface temperature of the plane gray layer where the error is also larger at low scattering and low absorption. It is shown that the accuracy of the diffusion approximation can be improved for some scattering and absorption conditions if a reflectance obtained from a Kubelka-Munk type two flux theory is used instead of a reflection obtained from the Fresnel equation. The Kubelka-Munk reflectance accounts for surface reflection and radiation scattered back by internal scattering sites while the Fresnel reflection only accounts for surface reflections.
\end{abstract}




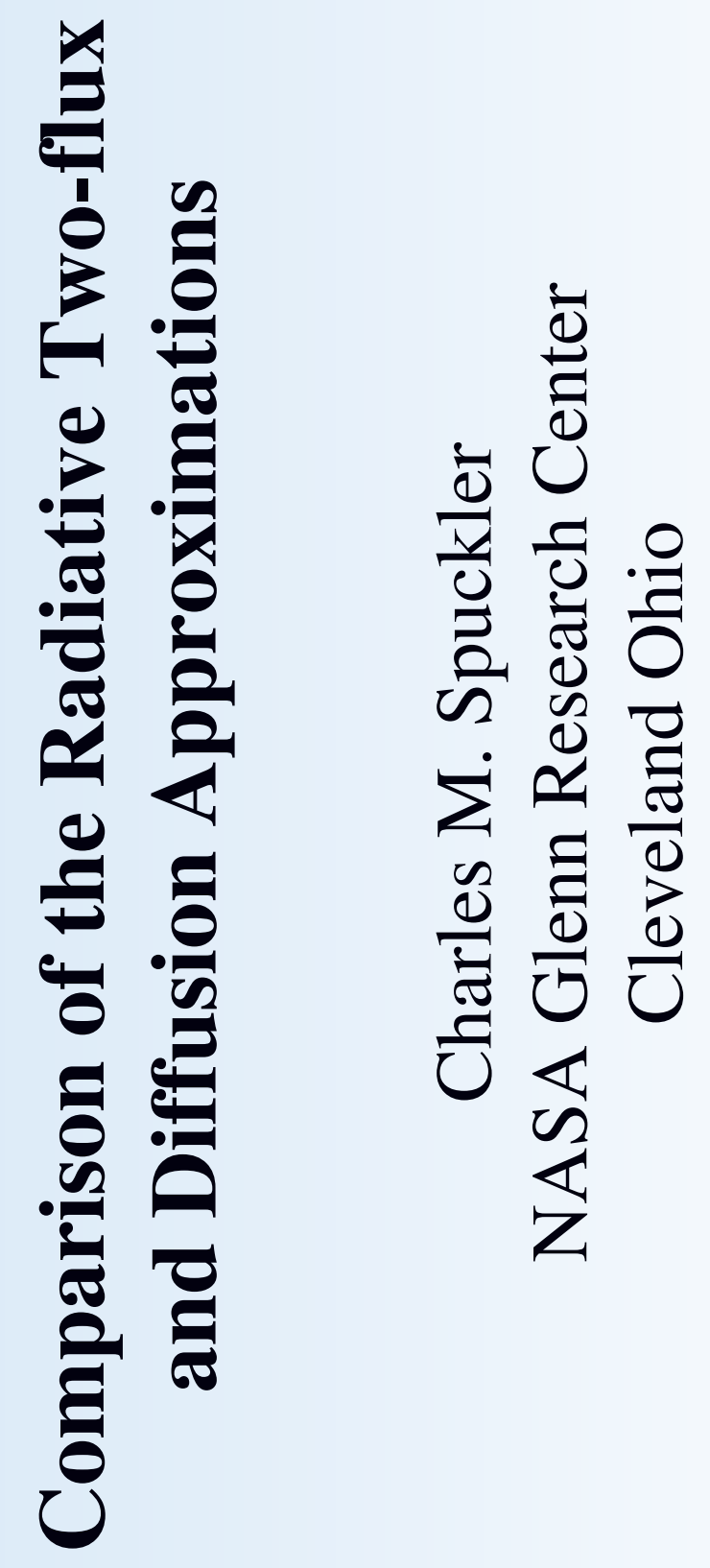




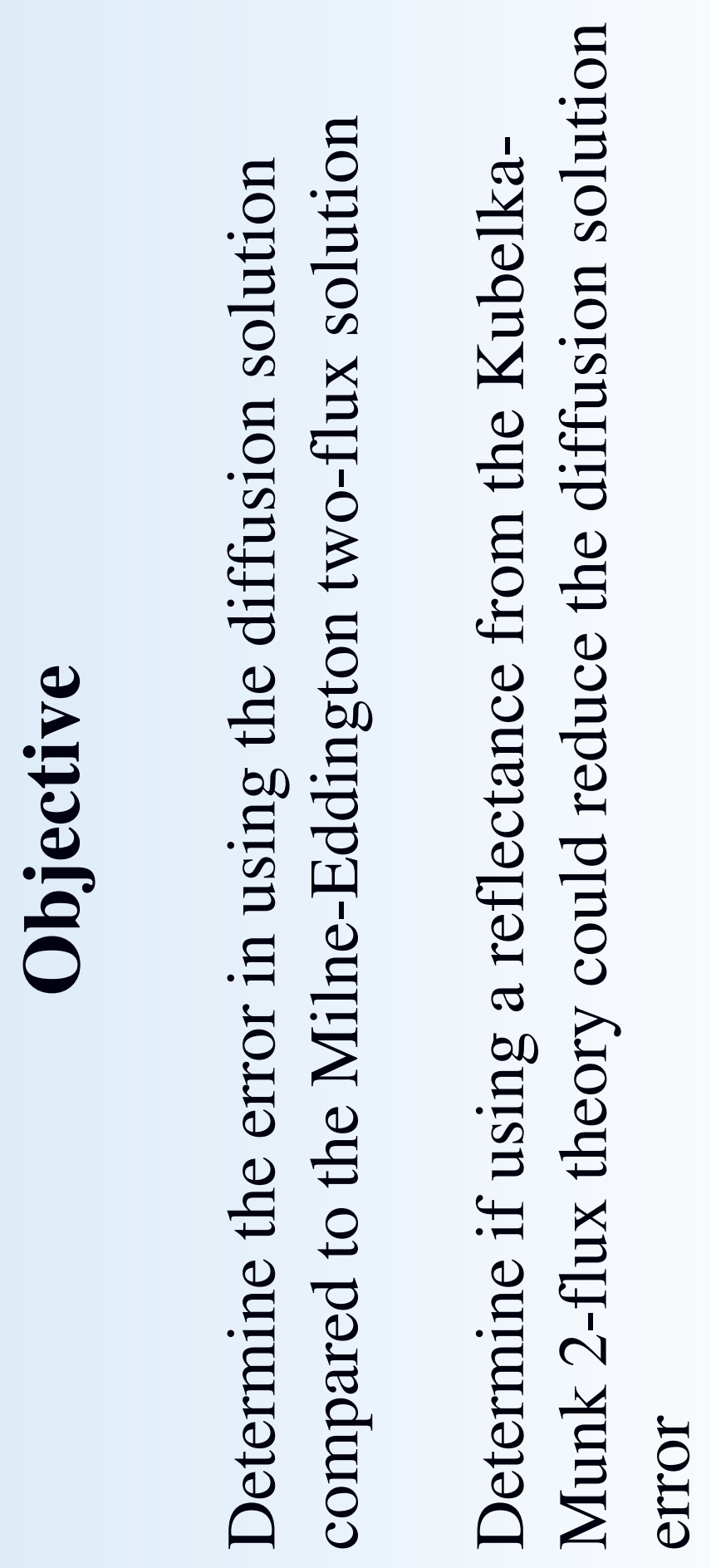




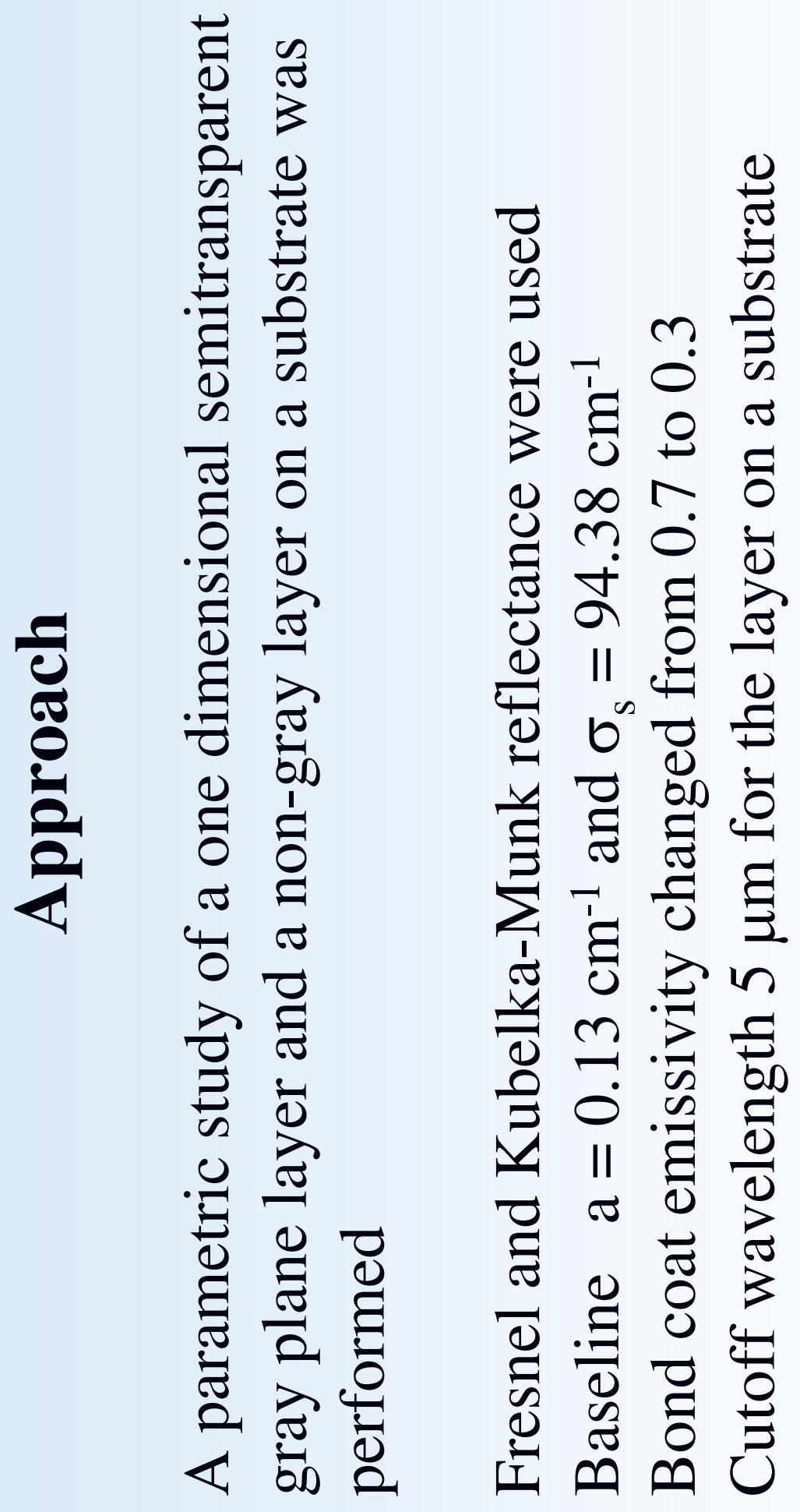




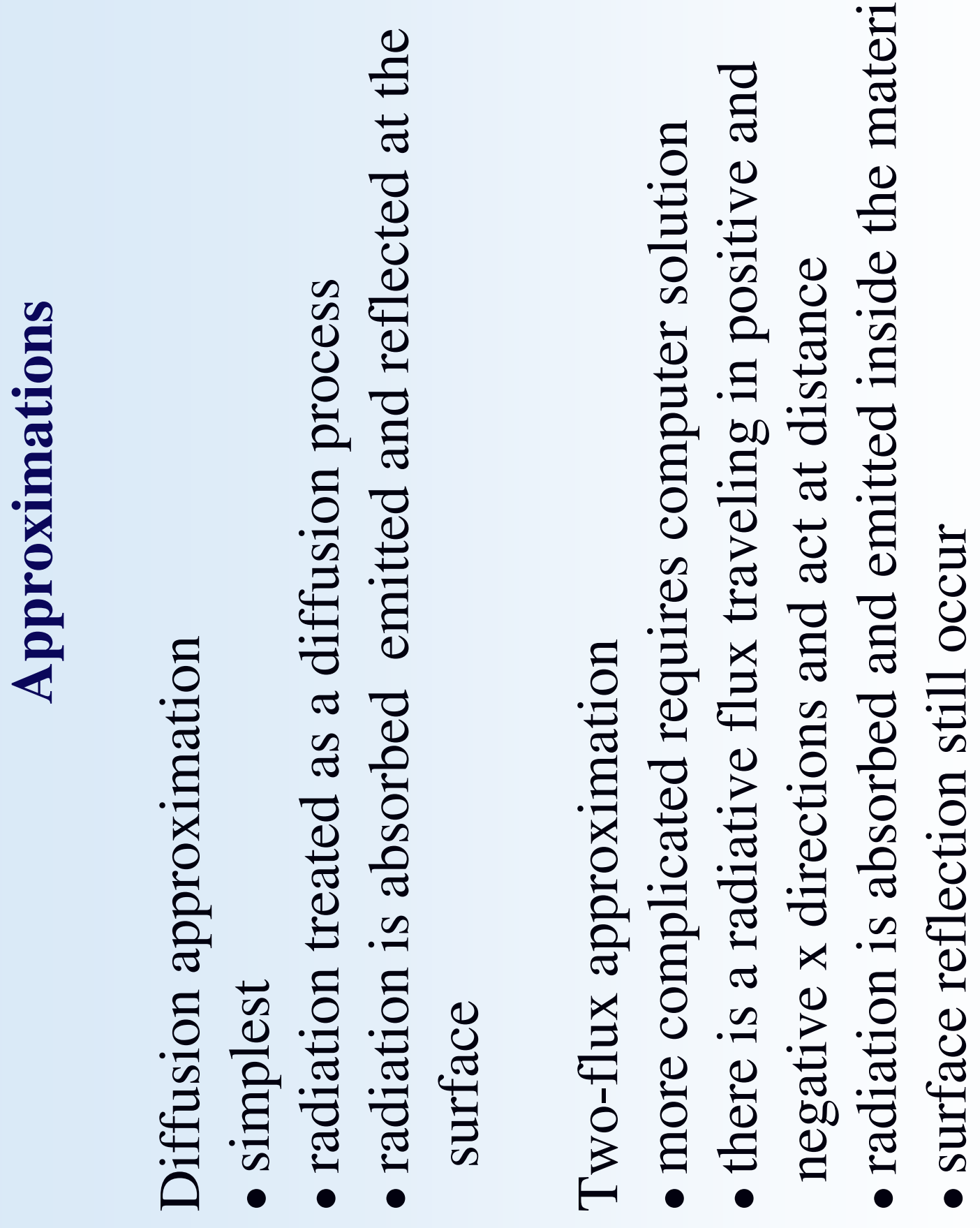




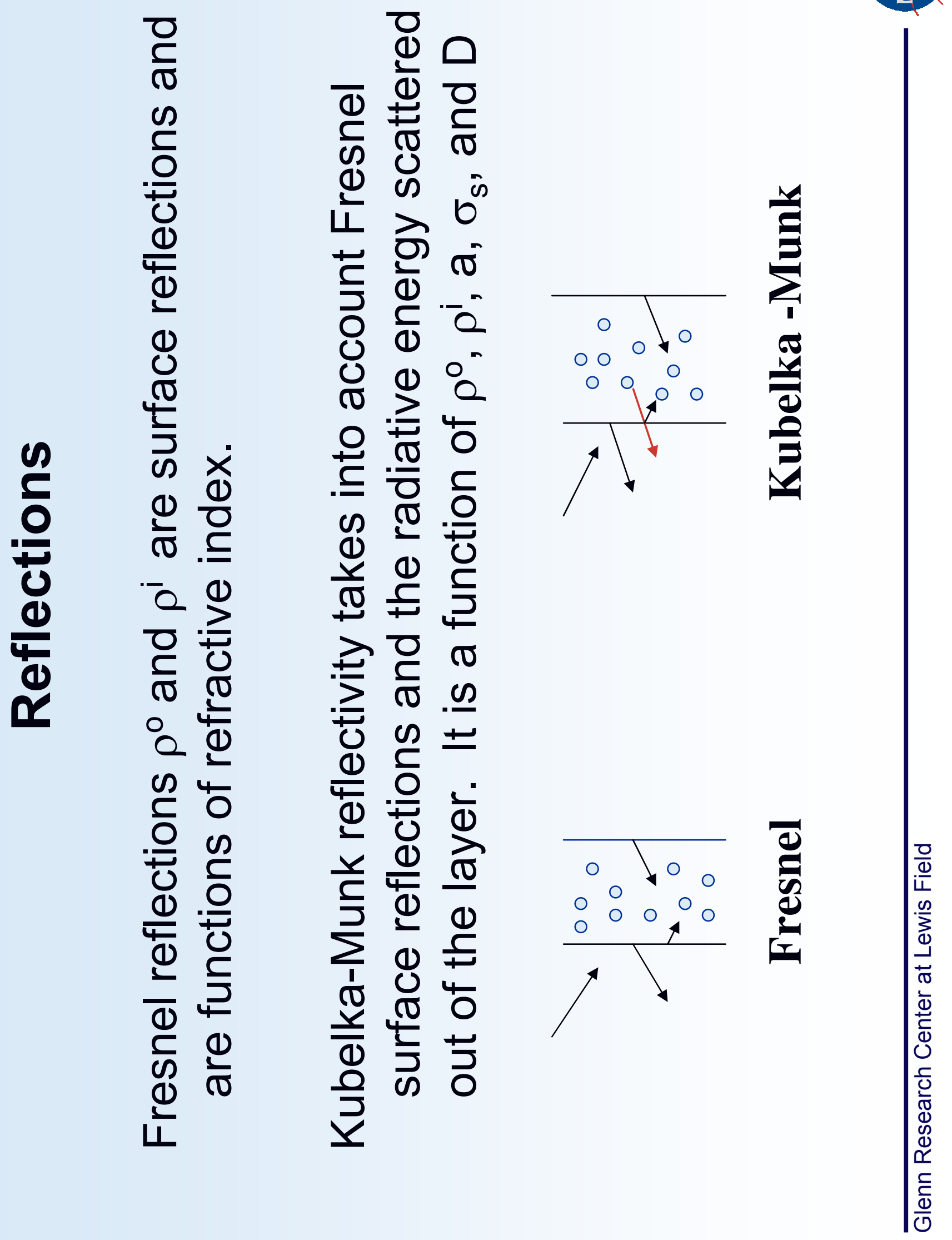




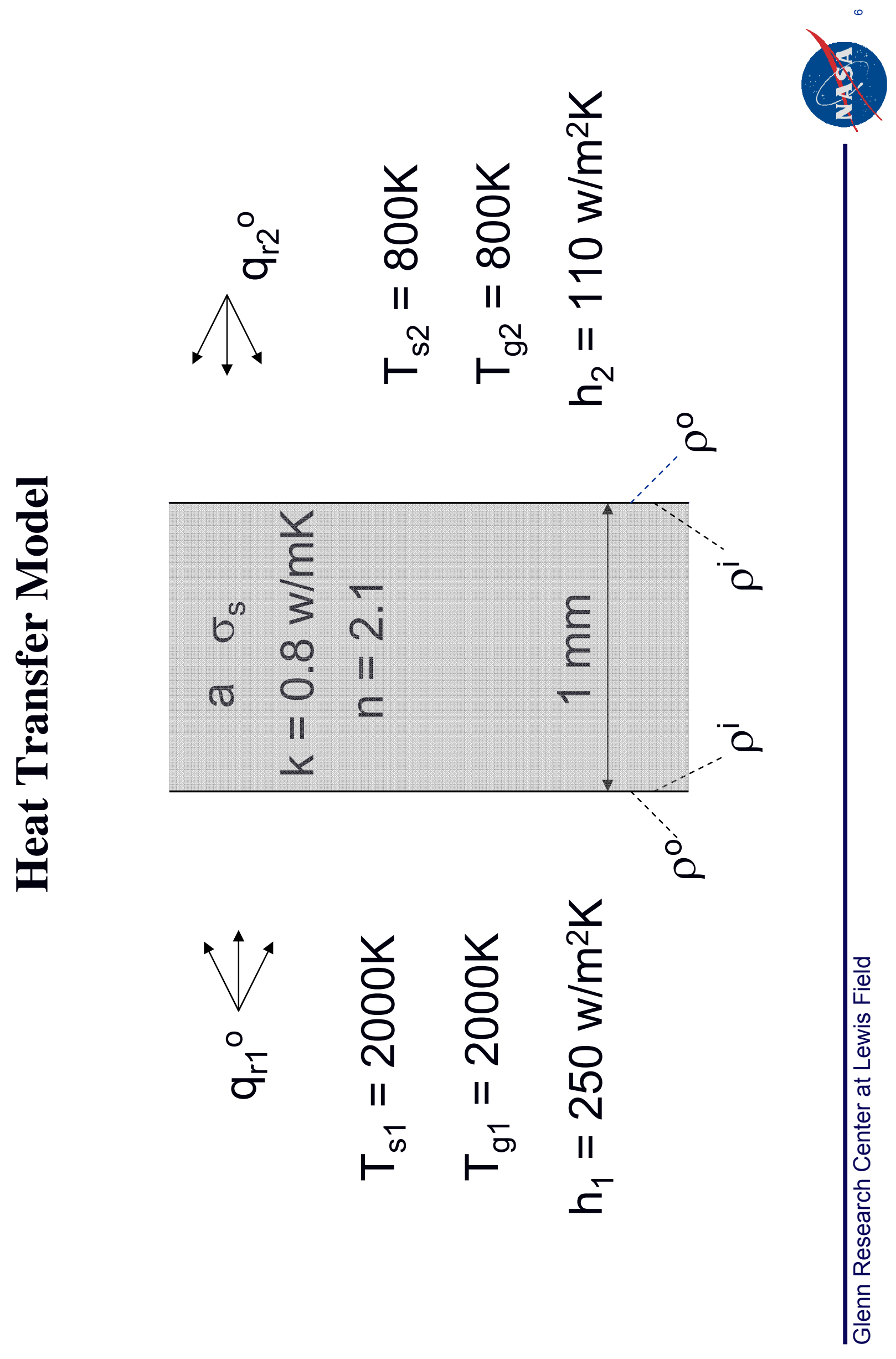




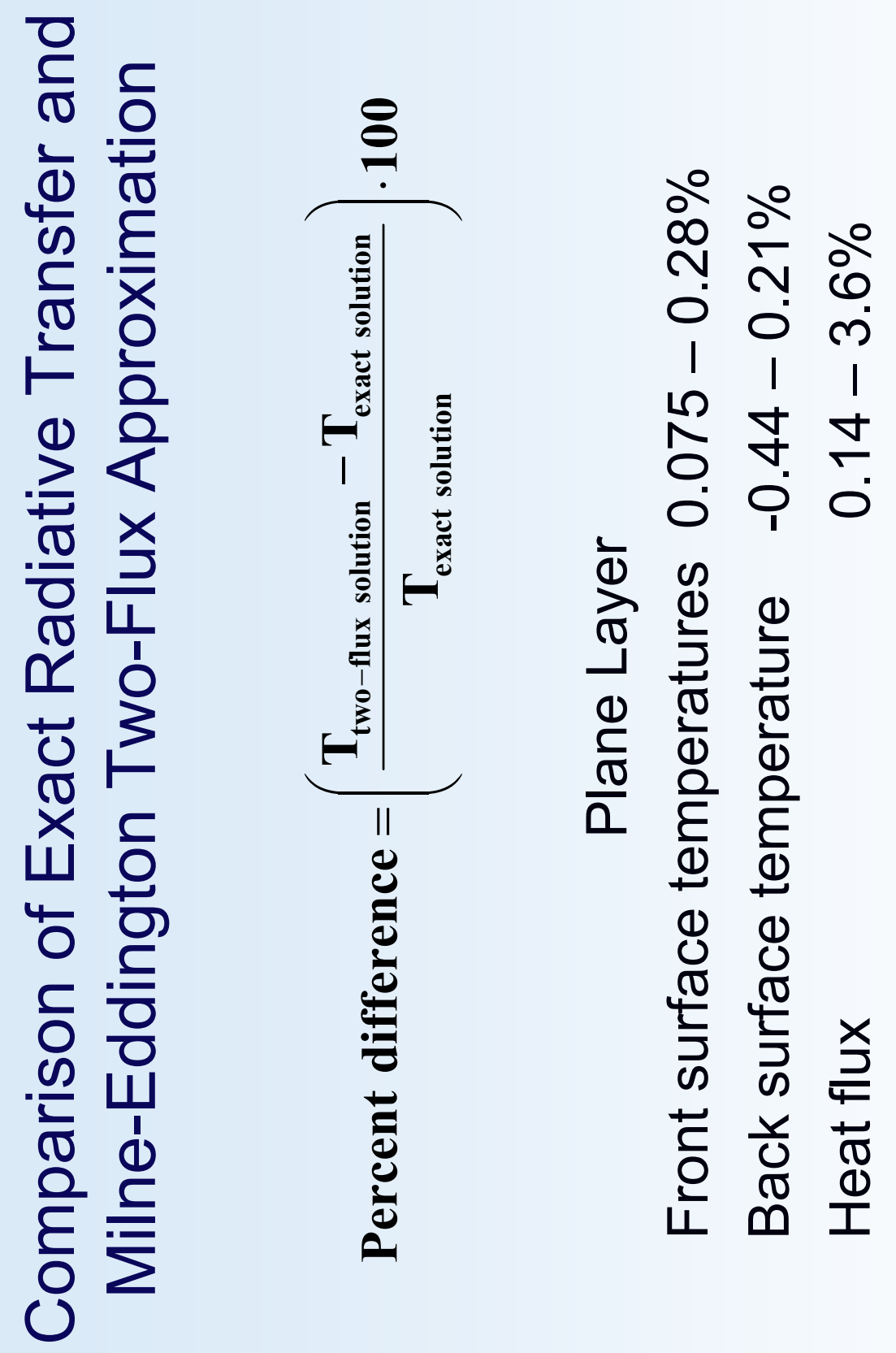




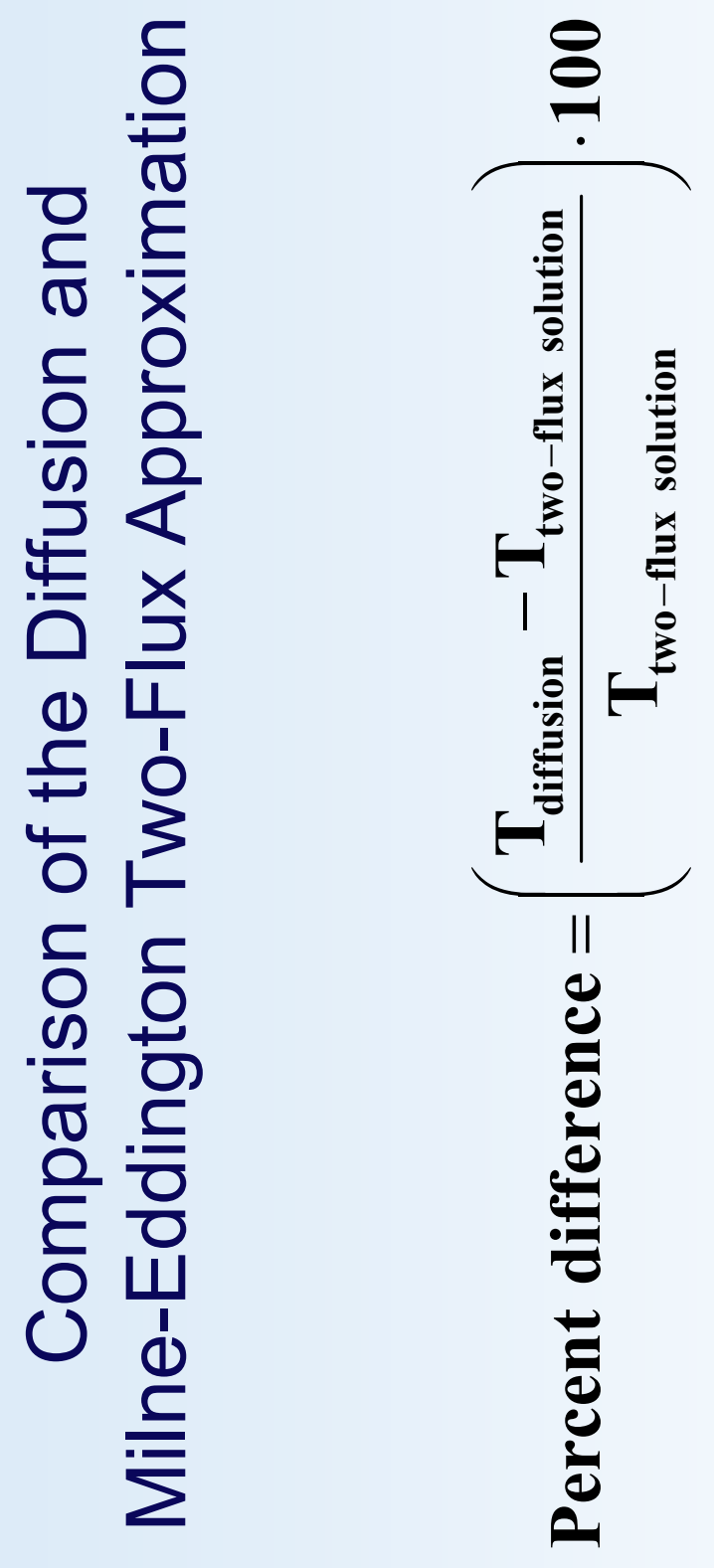




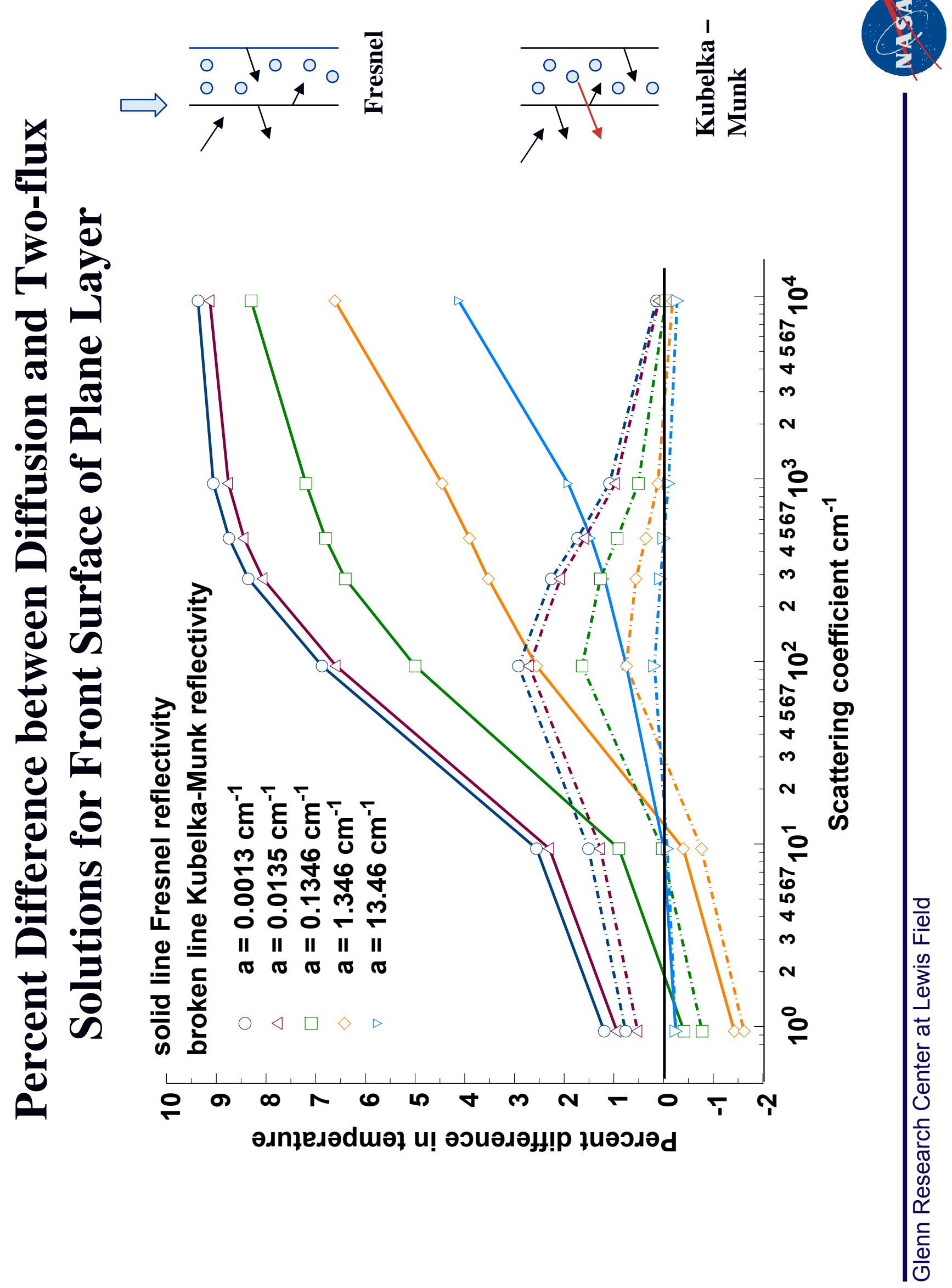



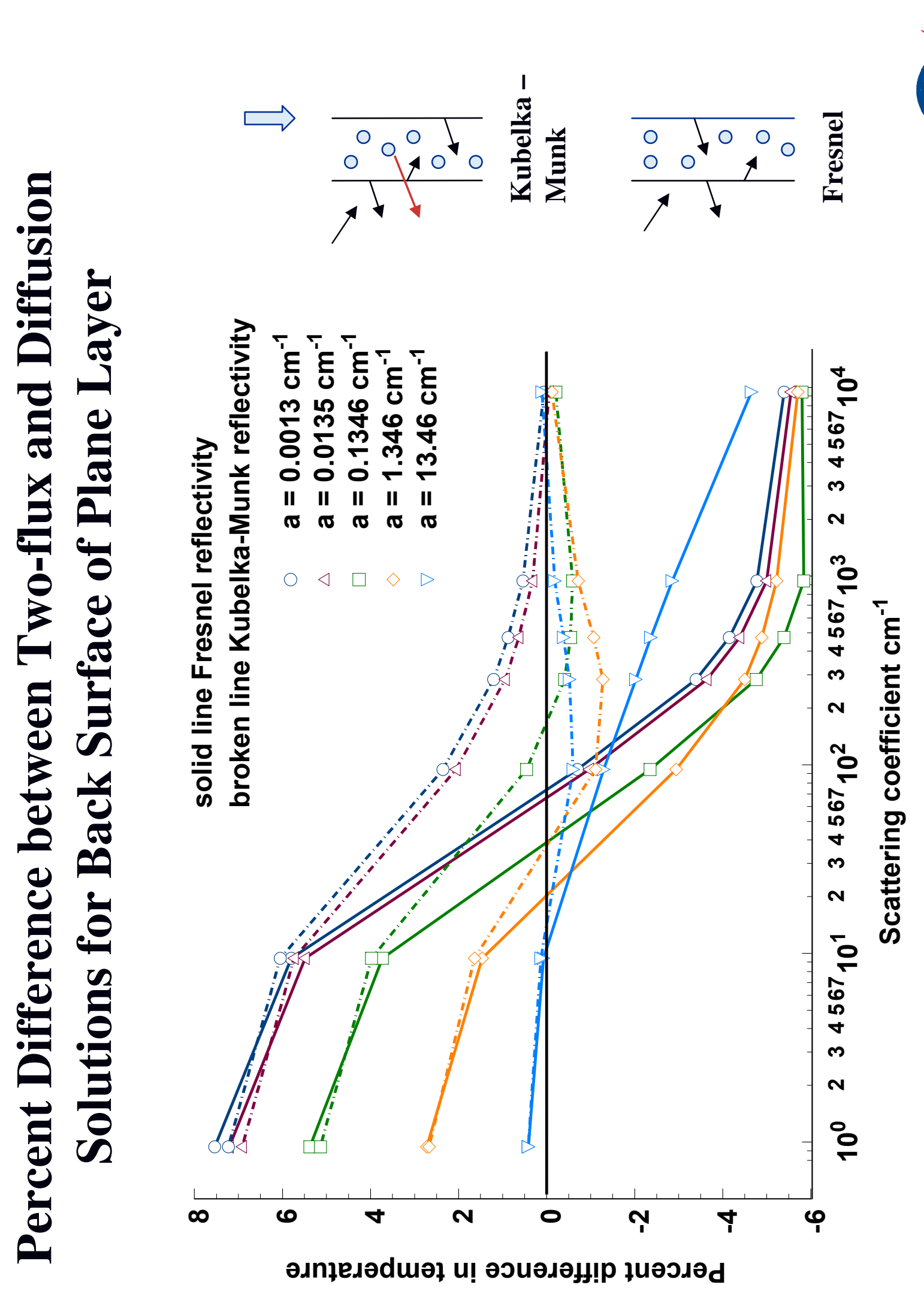


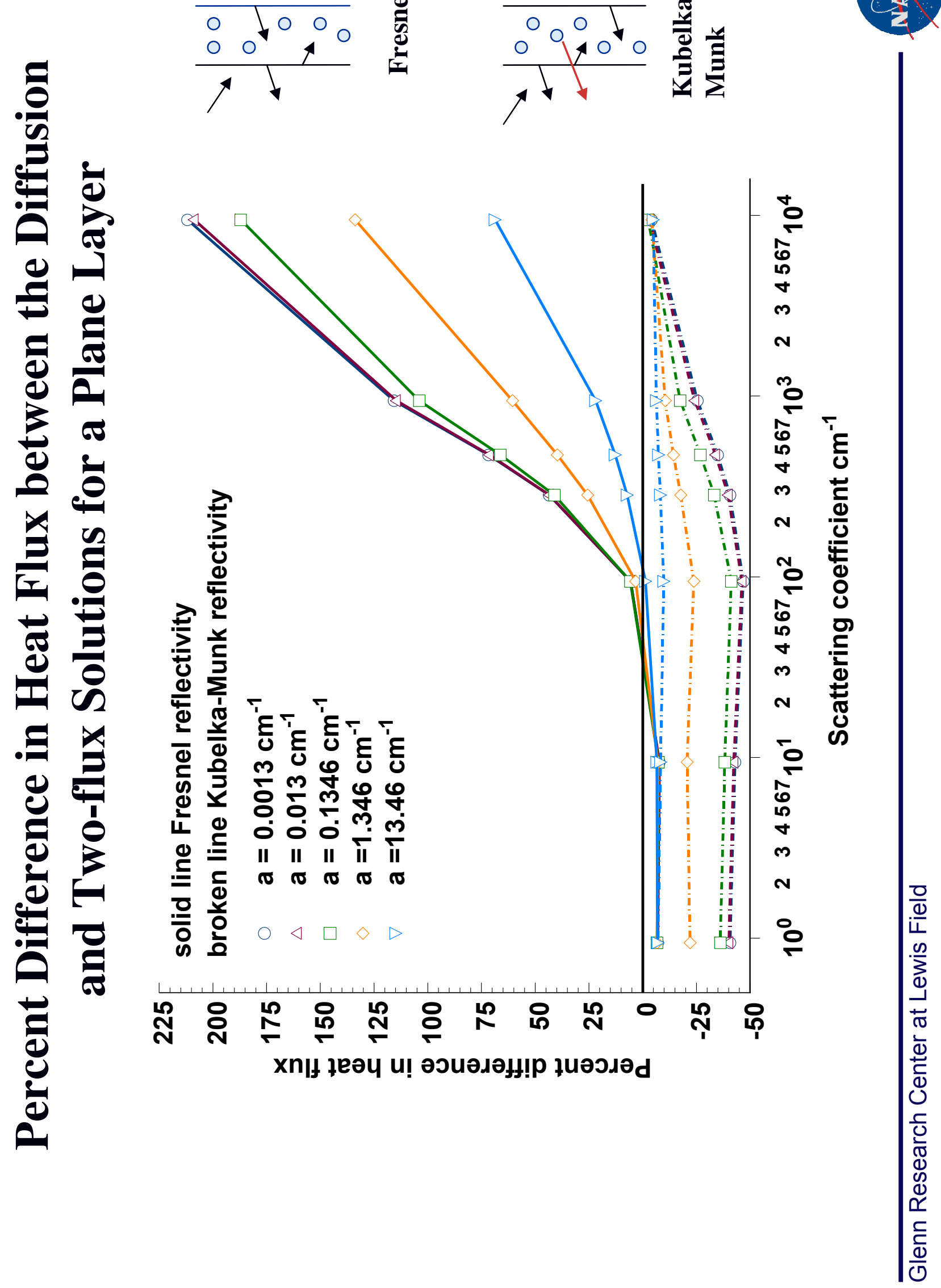




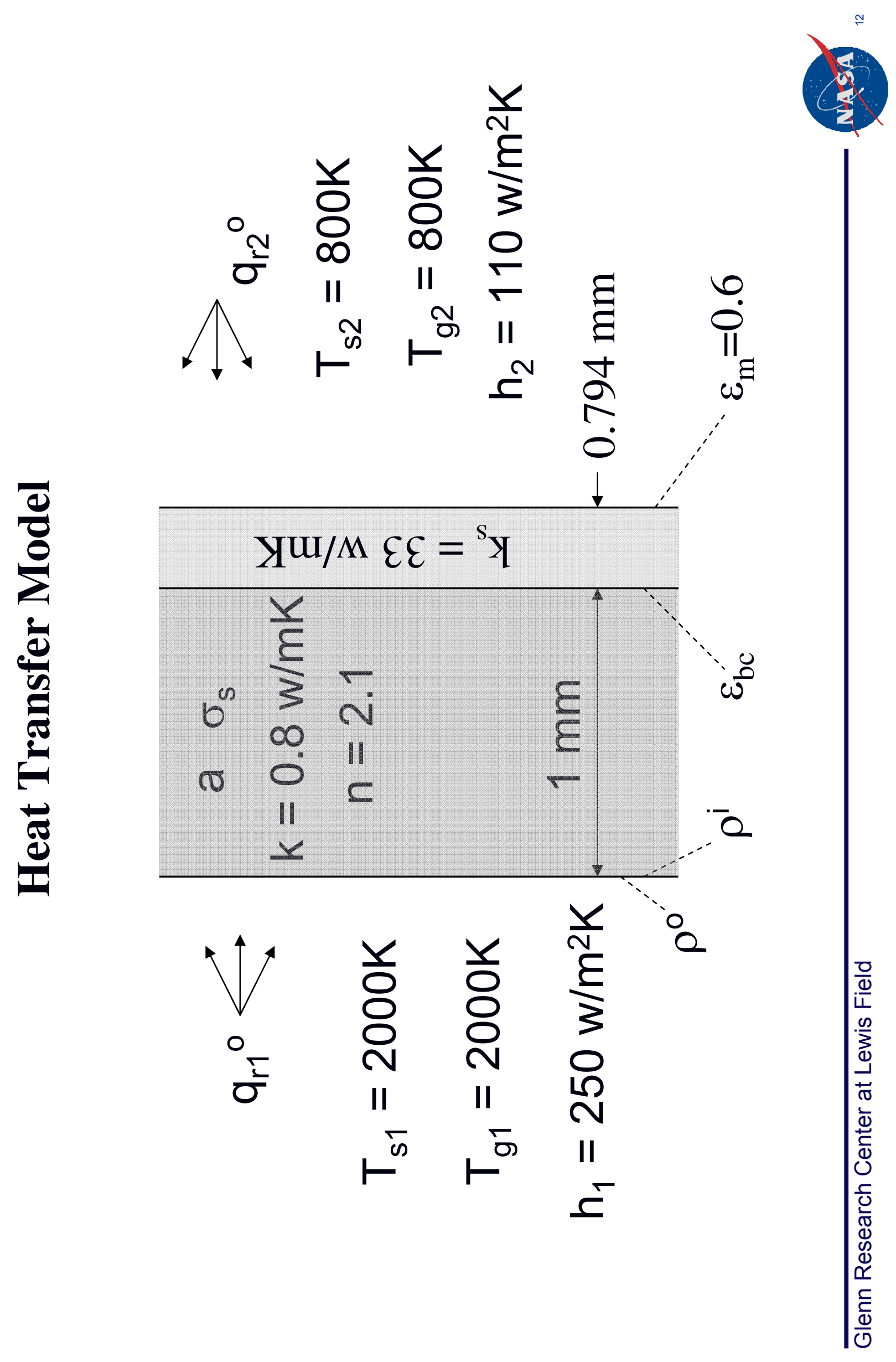



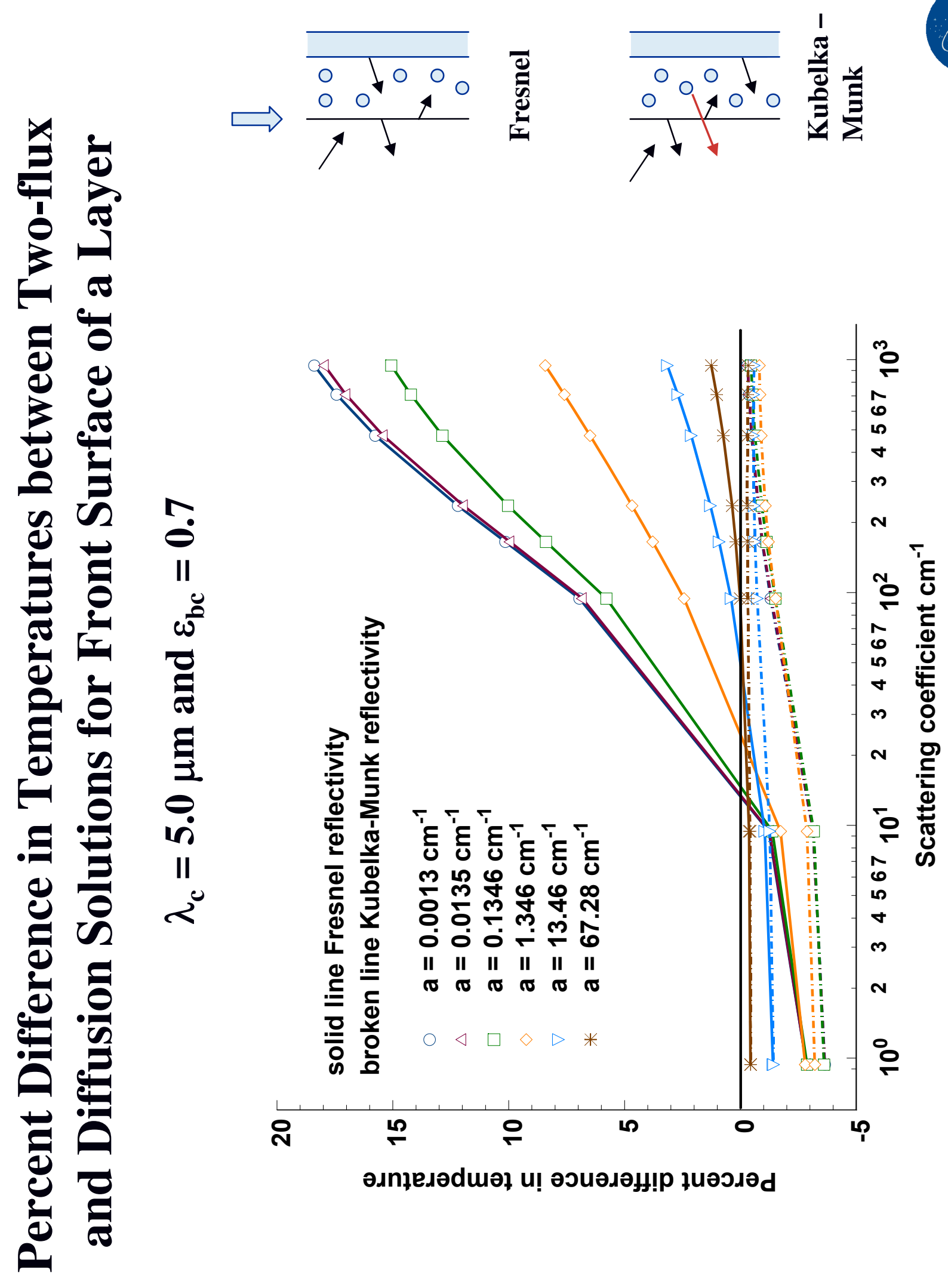

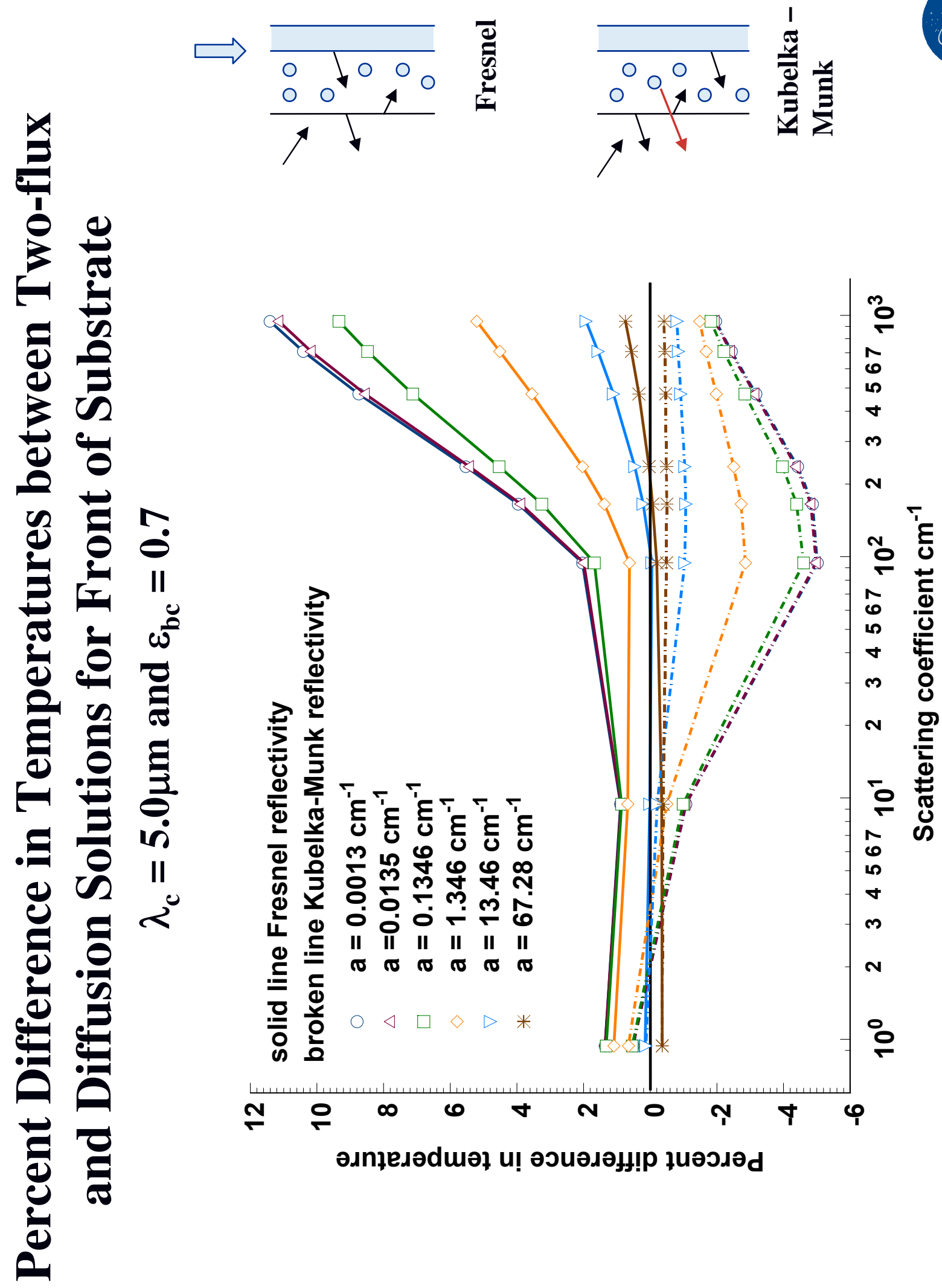

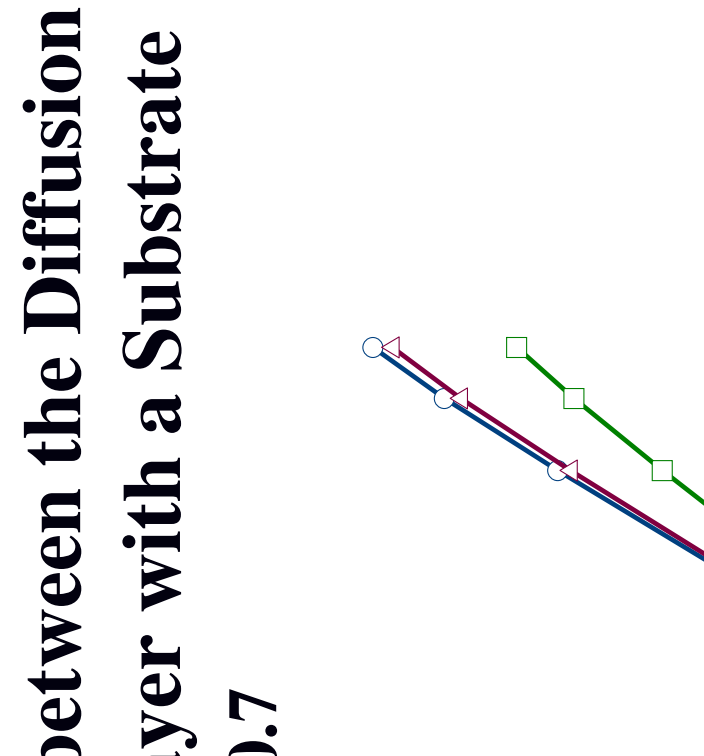

$x$ II
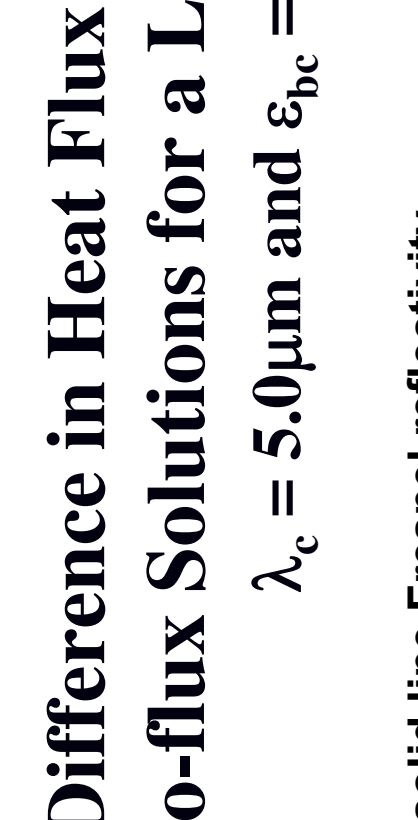

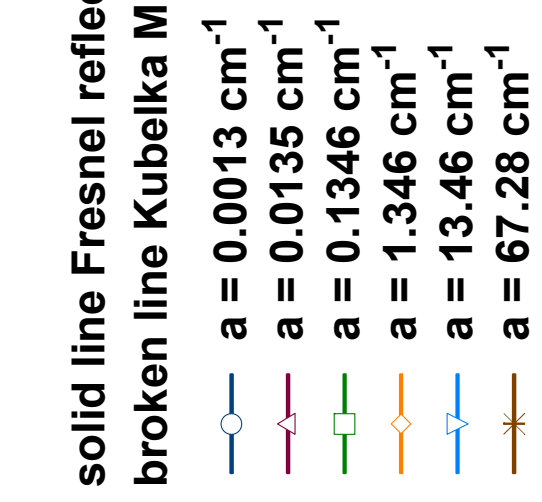

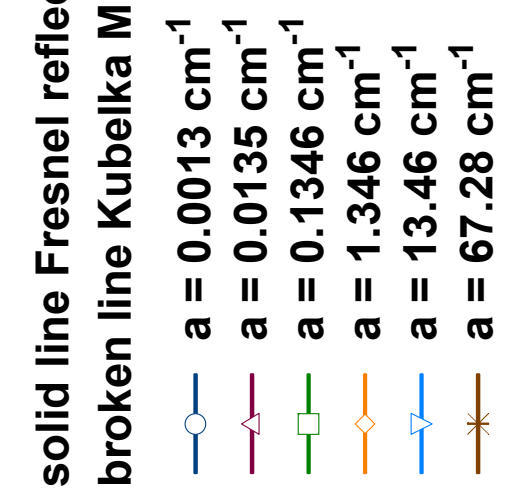

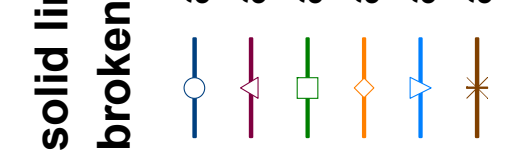

票

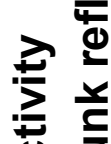

U.

(1)

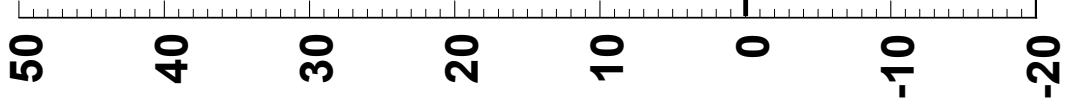

$\stackrel{m}{2}$

co

0

$\nabla$

$m$

N

2

은

N

0 (1)

$\checkmark$

m 8

N

을

in

寸

$m$

N

음

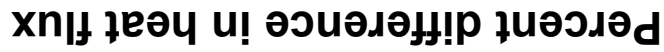



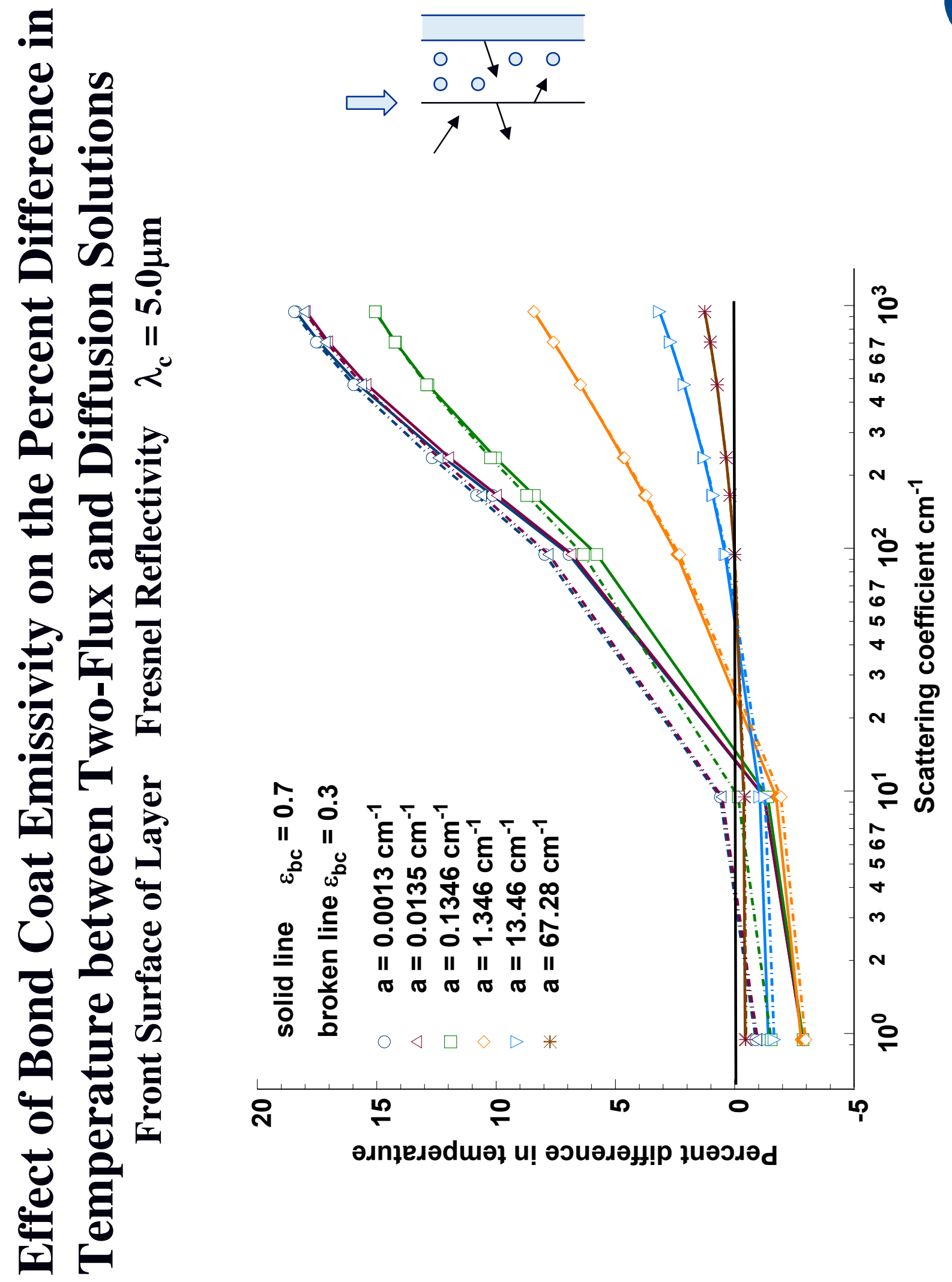

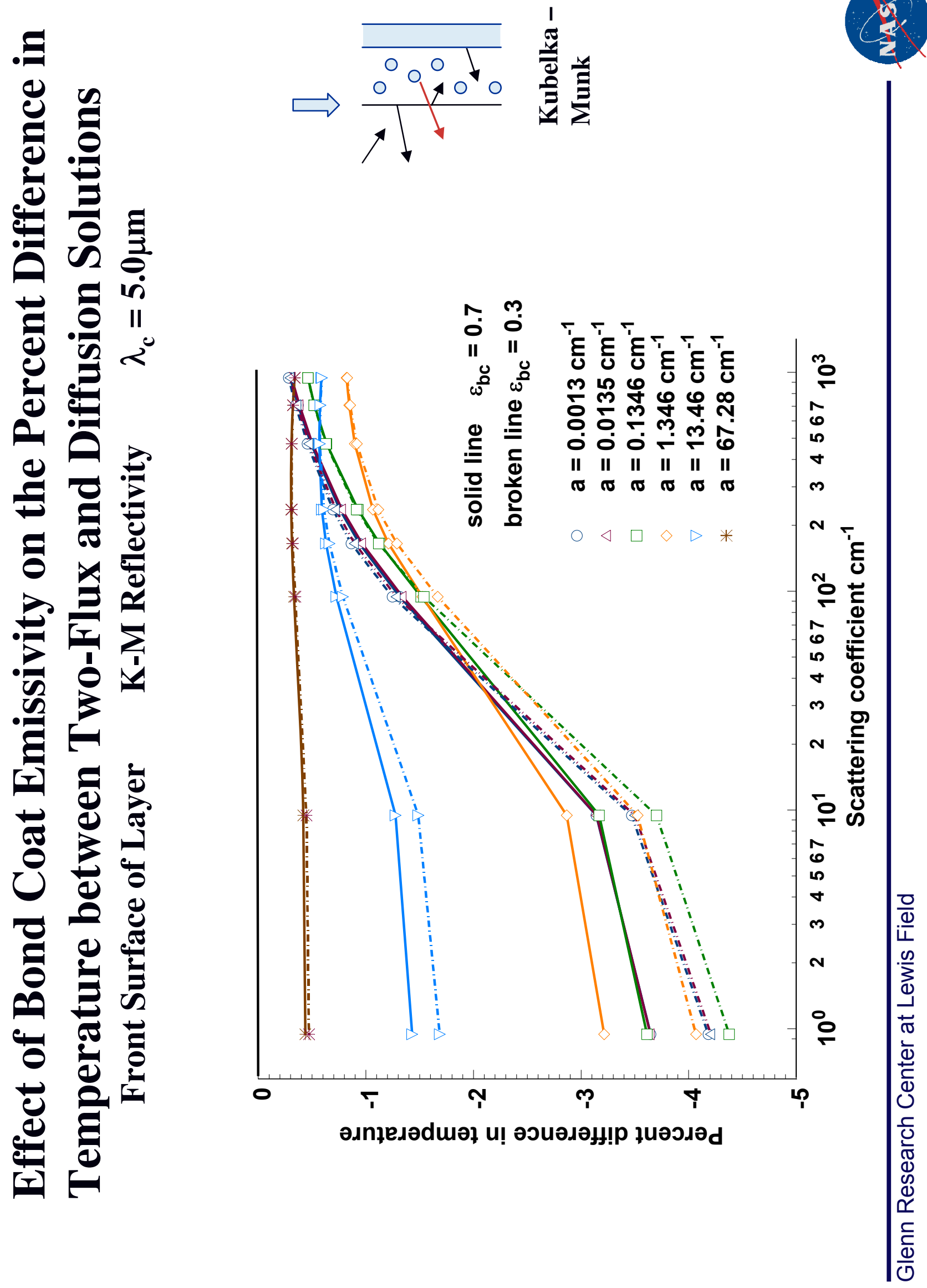


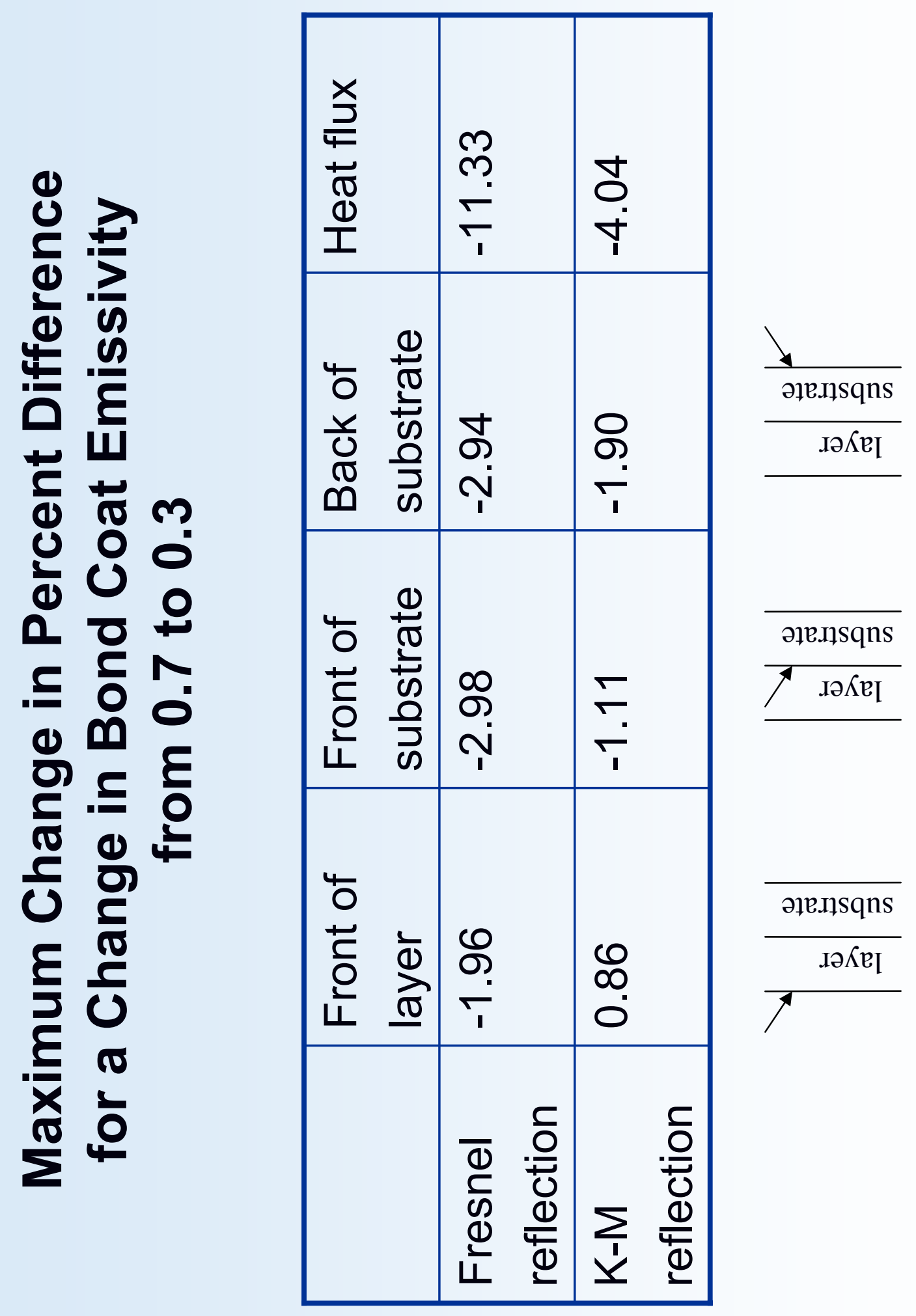




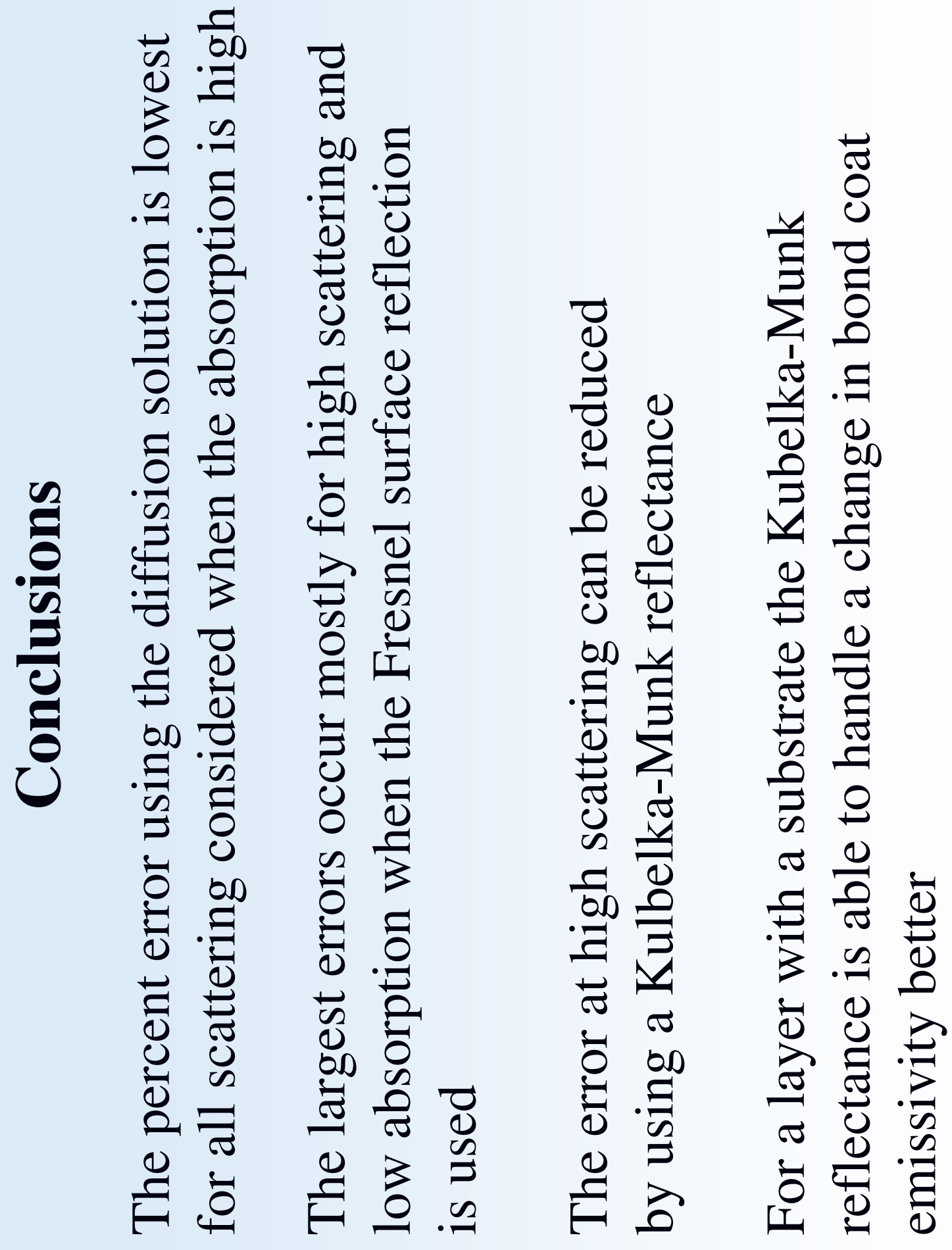




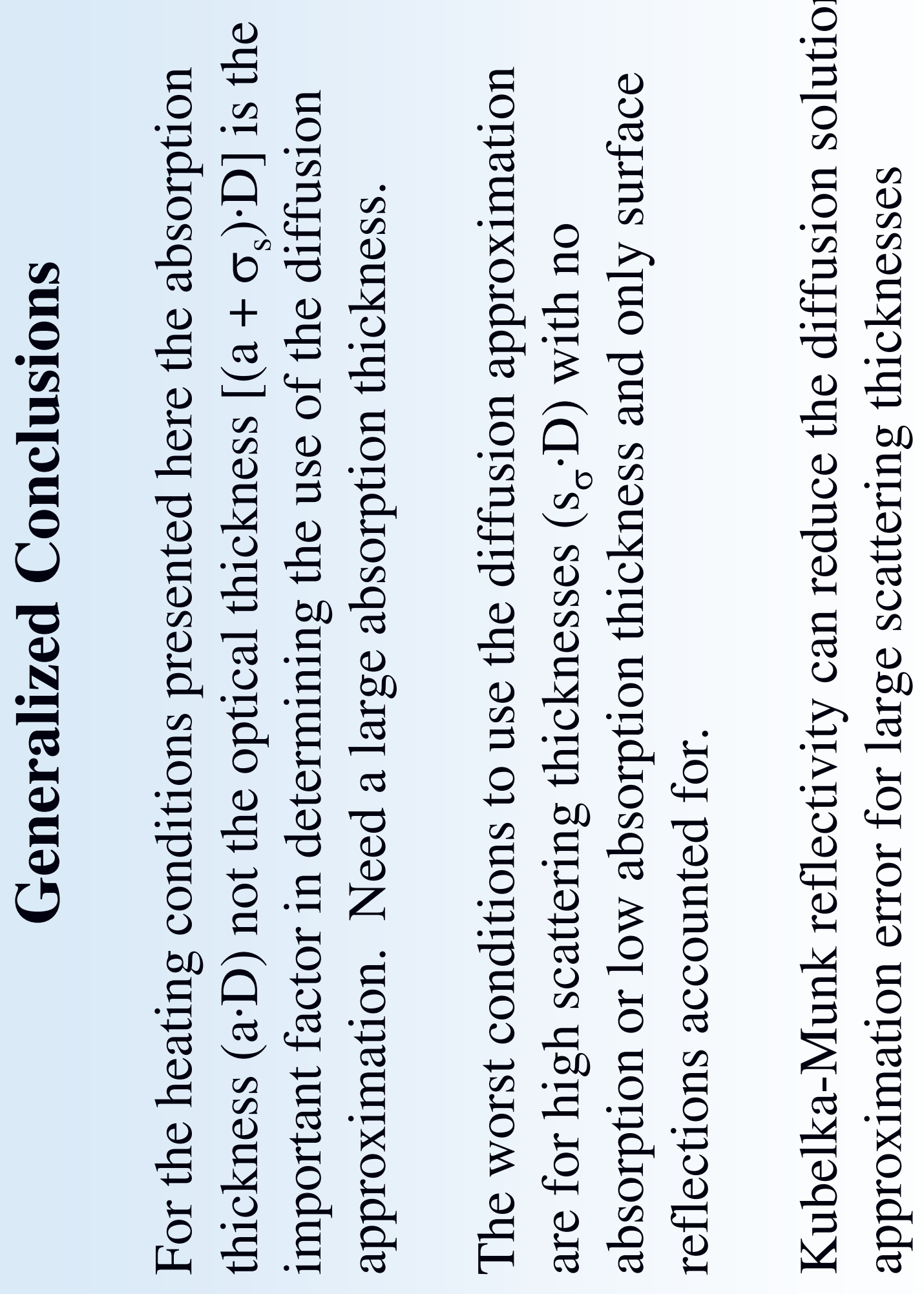

